\title{
Pilot Study to Gauge Acceptability of a Mindfulness- Based, Family-Focused Preventive Intervention
}

\author{
Larissa G. Duncan · J. Douglas Coatsworth • \\ Mark T. Greenberg
}

(C) The Author(s) 2009. This article is published with open access at Springerlink.com

\begin{abstract}
The purpose of the present study was to conduct a test of acceptability of a new model for family-focused drug prevention programs for families of early adolescents. An existing evidence-based behavioral intervention, the Strengthening Families Program: For Parents and Youth 10-14 (SFP), was adapted to include concepts and activities related to mindfulness and mindful parenting (an extension of mindfulness to the interpersonal domain of parent-child relationships). The foundation for this innovative intervention approach stems from research on the effects of mind-body treatments involving mindfulness meditation and the function of stress and coping in relation to parenting and parent well-being. One group of families participated in a seven-week pilot of this mindfulness-enhanced version of SFP. Results of a mixed-method implementation evaluation suggest that the new intervention activities were generally feasible to deliver, acceptable to participants, and perceived to yield positive benefits for family functioning and parent psychological well-being. The next phase of this research will involve curriculum refinement based upon results of this initial study, and a larger pilot efficacy trial will be conducted.
\end{abstract}

Keywords Mindfulness · Mindful parenting · Family · Adolescence · Preventive intervention

\author{
L. G. Duncan $(\bowtie)$ \\ University of California San Francisco, San Francisco, CA, USA \\ e-mail: duncanla@ocim.ucsf.edu \\ J. D. Coatsworth · M. T. Greenberg \\ The Pennsylvania State University, University Park, PA, USA
}




\section{Introduction}

A risk to parent well-being and optimal parenting may exist when intense periods of adolescent developmental change occur in the family system at the same time that parents are facing challenges associated with their own transition through midlife (Steinberg 2001; Steinberg and Silk 2002). For parents of adolescents, the ability to adapt to dramatic changes in adolescent physical, cognitive, and affective functioning and related behaviors (e.g., increased arguments and quest for autonomy) may be the key to avoiding disruption of their parenting and may increase parental well-being and reduce adolescent behavior problems and drug use. In comparison to young adulthood and older adulthood, midlife has been shown to be a time in the life course when there is a stronger association between work and family stress and levels of adult positive and negative affect (Mroczek 2004). In addition, levels of child negative affect rise during adolescence and there is evidence that adolescents transmit their negative affect to their parents (Collins 1990; Larson and Richards 1994).

The understanding that adolescence is a developmental period that involves substantial risk for maladaptive behavioral outcomes (e.g., delinquency, substance abuse; Hawkins et al. 1992), and that family factors are consistent predictors of adolescent functioning (Kumpfer et al. 1998), has prompted extensive efforts to prevent risk for negative outcomes (e.g., association with antisocial peers) and promote positive aspects of family functioning through skills-building (e.g., teaching effective parenting behaviors). As such, universal family-focused preventive intervention efforts to date have focused primarily on teaching parenting skills such as parental monitoring and the use of appropriate discipline techniques that have been demonstrated through basic and applied intervention research to be related to adaptive adolescent outcomes such as delayed initiation of substance use (Kumpfer and Alvarado 2003; Taylor and Biglan 1998).

In contrast, there has been relatively little attention paid in universal family skills training preventive intervention programs to the known, proximal determinants of parenting behavior such as parent emotions, social cognitions, and other aspects of parent psychological functioning (see Dix 1991; Dix et al. 1986). Even psychologically healthy adults experience an array of contextual demands such as financial strain, major life events, work-related stress, and interpersonal tensions that can negatively influence parenting (Conger et al. 1994). Many of these demands may be particularly salient during midlife (Mroczek 2004). When parenting challenges specific to parenting an early adolescent (e.g., the need to cope with increased youth argumentativeness and moodiness) are added to the stress parents experience in other domains of life (Silverberg 1996), learning new discipline practices may be insufficient to promote adaptive coping with the changing parent-adolescent relationship. What is more, parents who are experiencing psychological distress may not have adequate psychological resources to effectively employ the new parenting strategies that they have learned in preventive interventions in their moment-to-moment interactions with their children.

To begin to address this gap in the existing selection of evidence-based family skills training programs, we propose a new model for family-focused preventive 
intervention that involves integrating mindfulness into an existing evidence-based behavioral intervention program: The Strengthening Families Program: For Parents and Youth 10-14 (SFP; Molgaard and Spoth 2001). Although rigorous randomized controlled trial research shows that the program in its current form appears highly efficacious in altering adolescent substance use outcomes (delaying onset of use, reducing abuse) and building protective factors in the form of youth competencies, the only effects on parents that have been demonstrated are increases in the use of specific parenting behaviors (Spoth and Redmond 2002; Spoth et al. 2002, 2004). SFP has not been shown to influence parent well-being. We propose that integrating mindfulness into the curriculum is one approach that may achieve this additional, desired program outcome. Furthermore, teaching mindfulness practices to parents may enhance the program's effects on parenting (e.g., improved affective quality of the parent-child relationship) and subsequently, may improve child outcomes to an even greater degree than was found with the original SFP program.

Mindfulness has been used in the discipline of psychology to describe "...a theoretical construct (mindfulness), a practice of cultivating mindfulness (such as meditation), or a psychological process (being mindful)" (Germer 2005, p. 6). Over the past 30 years, clinicians and researchers in the psychological and medical sciences have increasingly explored both secular and non-secular aspects and applications of all three of these forms of mindfulness. Most notably, a secular approach to teaching mindfulness meditation as a treatment for stress reduction, the Mindfulness-Based Stress Reduction program (MBSR; Kabat-Zinn 1990, 2003), has achieved widespread appeal since its inception in 1979. The core of mindfulness involves intentionally bringing moment-to-moment awareness to the present experience with a nonjudgmental stance (Kabat-Zinn 2003). Burgeoning clinical research studies are yielding evidence that a variety of mindfulness-based intervention approaches may considerably alleviate psychological distress (e.g., anxiety and depression) and promote psychological well-being for individuals experiencing chronic and acute stress and illness (Baer 2003; Kabat-Zinn 2003).

Teaching mindfulness-based practices to parents has the potential to improve parent emotion regulation and parents' ability to cope with the stress and emotional complexity of raising a young teenager. We propose a model for family prevention that explicitly takes into account the affective and cognitive determinants of high quality parenting by equipping parents with mindfulness practices that can promote adaptive coping. Parents who learn mindfulness practices may also be better prepared to support their children in navigating the normative developmental challenges of identity exploration and individuation found in adolescence. Further, we espouse an intervention change model by which family prevention programs may influence greater health and well-being among all participants: adolescents and their parents.

\section{Incorporating Mindfulness into Family-Focused Preventive Interventions}

As a framework for the present intervention pilot study, we propose that family prevention programs can be developed that effectively incorporate mindfulnessbased practices in order to: (a) break the link between intra- and extra-familial 
contextual demands and adult negative affect found in midlife, (b) teach parents how to observe and become aware of mounting interpersonal tensions before they arise, (c) help parents to reduce their own reactivity to negative affect expressed by their teen, and (d) encourage parents to behave with the caring and compassion that stems from deep empathy and emotional perspective taking. Adding these components to family skills training for families of adolescents could serve to improve parent mindfulness, mindful parenting, psychological well-being, coping, emotional and metacognitive awareness, and self-regulation. If these specific mediators are impacted, models of the determinants of parenting (Abidin 1992; Belsky 1984), Stress and Coping Theory (Lazarus and Folkman 1984; Folkman 1997), and basic research on the effects of stress on health suggest that we can expect an improvement in parent health and well-being and a substantial improvement in the quality and effectiveness of parenting behaviors.

Framework for the Intervention

As this was uncharted territory when we began, our first step was to explore the acceptability of incorporating mindfulness into a structured family skills training program. Rather than develop an entirely new mindfulness-based family intervention, we chose to adapt the SFP (Molgaard and Spoth 2001), an existing, empirically validated, family-focused preventive intervention, by infusing the program with mindfulness concepts and practices related to parenting (with permission from the program developers). We identified SFP as the ideal target for this adaptation because: (a) its content links clearly with the central dimensions of mindfulness in parenting; (b) its format is conducive to integrating mindfulness practices; (c) it has strong empirical evidence showing its ability to deter the onset of adolescent substance use (Spoth et al. 2002); (d) it has been recognized as a model program by the Center for Substance Abuse Prevention and the Substance Abuse and Mental Health Services Administration and as an exemplary program by the U.S. Department of Education and the Office of Juvenile Justice and Delinquency Prevention; (e) other research groups have successfully adapted it for use with minority groups in the U.S. and for international populations; and (f) it has a wellestablished system for facilitator training, program implementation (including welldocumented participant recruitment and retention; Spoth et al. 2007), and dissemination in over 35 U.S. states and several international sites.

\section{The Application of Mindfulness to Parenting}

The Western conceptualization of mindfulness as a psychological process and as a meditation practice entails bringing awareness and attention to the constant stream of cognitive, emotional, and somatic experiences while maintaining a nonjudgmental and accepting stance (Bishop 2002; Germer 2005; Kabat-Zinn 2003). As the guiding conceptual framework for our curriculum adaptation of SFP, we have elsewhere proposed a construct of "mindful parenting" based upon the work of Kabat-Zinn and Kabat-Zinn (1997) and our synthesis of the parenting, mindfulness, and intervention research literatures (see Duncan et al. 2009). Mindful parenting 
may have great utility as a targeted mediator when intervening with families of early adolescents. The concepts and practices of mindfulness appear to be readily applicable to the daily tasks of parenting (Kabat-Zinn and Kabat-Zinn 1997) and may improve family intervention efforts (Dumas 2005), although we are just beginning to test this empirically. Furthermore, mindfulness-based practices such as those employed in MBSR have been successfully transferred from a treatment paradigm into a relationship-strengthening, preventive intervention framework in Mindfulness-Based Relationship Enhancement (Carson et al. 2004, 2006).

"Mindful parenting" is conceptualized as a higher-order construct that encompasses parent caring and compassion (beyond the simple expression of affection), parent social cognitions (Dix et al. 1986), and awareness of and reactions to parenting-related emotions (Dix 1991; Gottman et al. 1996). By extending mindfulness to the interpersonal interactions taking place during parenting, mindful parenting is hypothesized to represent qualities of the cognitive-affective interface occurring for parents during moment-to-moment parenting interactions with their children. Core aspects of mindful parenting include: (a) listening with full attention, (b) maintaining emotional awareness of oneself and one's child during parenting interactions, (c) practicing nonjudgmental openness and receptivity when children share their thoughts and feelings, (d) regulating one's own automatic reactivity to child behaviors, and (e) adopting compassion towards oneself as a parent and toward the struggles one's child faces (e.g., in becoming a teenager).

Incorporating these five dimensions of mindful parenting into parenting interactions in the moment should both facilitate more effective parenting practices and lead to a reduction in potentially disruptive parenting practices. If parents listen to their child with full attention, they may be more likely to correctly discern their child's behavioral cues, more accurately perceive the underlying meaning and personal significance of their child's verbal communication, and become less reliant upon the use of the cognitive constructions and expectations that can cause coercive cycles or automaticity in parenting (Dumas 2005). Bringing nonjudgmental acceptance to parenting may encourage a healthy balance between child-oriented, parent-oriented, and relationship-oriented goals, and a reduction in self-directed concerns on the part of the parent. This dimension of mindful parenting may lead parents to have a greater sense of parenting self-efficacy and a greater appreciation of the traits of their child, along with fewer unrealistic expectations for their child's attributes or abilities at the developmental stage of early adolescence. Parental awareness of their own affective experiences and those of their teen during parenting interactions may lead to an increase in their responsiveness to child needs and a reduction in the use of harsh discipline that can occur when parents are overwhelmed by their own strong negative affects such as anger or shame.

Parents who are able to bring greater self-regulation to the parenting relationship may become better able to avoid overreactive or "automatic" discipline, and they may be better equipped to parent in accordance with their goals and values around parenting. Finally, creating a parenting context that is built upon compassion for oneself as a parent and for the struggles one's child faces may lead to more frequent displays of positive affect and less frequent negative affect during parent-adolescent interactions. Parents who adopt a stance of greater self-compassion may also take a 
more forgiving view of their own parenting efforts, with less self-blame when they do not achieve their parenting goals, which may ultimately lead to a more resilient ability to reengage in the pursuit of parenting goals that are not met with immediate success.

\section{New SFP Mindfulness Activities}

Our initial adaptation of SFP involved developing new mindfulness-based program activities that were infused into the existing parent-only portion of the curriculum. This was accomplished by making additions to the current content with no content deletions. These new activities mapped onto the aforementioned dimensions of mindful parenting and they were intended to increase participants' mindfulness in parenting. The new activities incorporated into SFP were as follows.

\section{Listening with Full Attention}

During each session of SFP, parents were invited to focus their attention through brief periods of mindfulness practice. Parents were asked to sit comfortably such that they could be alert, and they were invited to close their eyes if they wished, and bring their awareness to some aspect of their present experience, such as focusing on the breath. Examples of the point of focus in these activities varied, with some mindfulness practice devoted to noticing thoughts related to parenting or recent interactions with their children. Parents were taught skills for bringing attention and awareness to communicating in the moment with their children.

\section{Emotional Awareness of Self and Child}

New activities were added to SFP that target awareness of the emotions of parenting by teaching parents how to observe, recognize, and label their parenting-related emotions. Parents practiced observing their affective experience when alone and during parenting interactions and they practiced observing the subtle emotional expressions made by their child and the ways in which their moods were affected by their child's mood.

\section{Nonjudgmental Acceptance of Self and Child}

Parents were guided in a variety of activities in which they reflected on the commonalities and differences between themselves and their youth. They were asked to bring awareness to their child's needs and characteristics. They were also asked to investigate the kinds of attributions and judgments they make about themselves and their child and then begin to make connections between how those judgments relate to relationship patterns and then to the quality of the parent-child relationship.

\section{Self-Regulation in the Parenting Relationship}

The first skill targeting this dimension of mindful parenting is mindful attention and awareness; parents were also taught to return to the breath when they experience 
escalating emotions. Parents were taught that physiological stress reactivity can have physical signs such as a more rapid heart beat, and that if they make an effort to notice those signs, they can make wise choices to calm themselves down before making parenting decisions.

\section{Compassion for Self and Child}

Throughout the mindfulness-enhanced SFP, we incorporate themes of caring and compassion. The original SFP curriculum contains the major theme of balancing warmth and discipline in the parenting relationship by balancing "love and limits." We expanded upon this concept by infusing the curriculum with brief compassion and loving-kindness practices designed to bring about greater empathy and caring for the difficulties of being an adolescent and greater self-compassion for the difficulties of being the parent of an adolescent. Parents were also encouraged to identify and reflect on aspects of their parenting that they feel good about and to avoid judging themselves harshly when they do not immediately meet their goals in parenting.

\section{The Current Study}

The current study was undertaken through a partnership with a local Communities That Care ${ }^{\circledR}$ (CTC) collaborative prevention board. The CTC board is comprised of directors of local youth and family service organizations and representatives of three member school districts whose populations it serves. At the time the study began in 2006, the CTC board was seeking state-level funding to implement SFP on a large scale; because SFP had not previously been delivered in the local community, the board sought to benefit from the district-specific implementation knowledge we would gain from this pilot. All three school districts were offered the opportunity to be the site of this pilot project, all three accepted, and the pilot was conducted in the district that was the first to make contact. Although SFP is developmentally appropriate for delivery to youth between the ages of 10-14, the focus of this pilot was narrowed to youth in the sixth grade (average age 11.5 years).

Primary research questions for the pilot were: (a) Can mindfulness-based practices be effectively integrated into a universal, brief family-focused preventive intervention?, (b) Will parents be receptive to concepts and practices of mindfulness and mindful parenting?, and (c) Will parents perceive the curriculum additions to be beneficial for improving parenting and relieving family stress?

\section{Method}

\section{Sample Recruitment}

Parents were recruited through the local school district. Letters were mailed home to all parents of sixth grade students, and a presentation was made to the middle school parent-teacher association. Enrollment was limited to five families in order to ensure a small enough group size that each parent participant would have sufficient 
time to actively participate in the interactive portion of each of the new curriculum activities. Incentives were offered in the form of a family dinner before each session, childcare for younger siblings, and attendance gifts (e.g., family board games, movie coupons, etc.). The first five families who expressed interest were enrolled in the study (i.e., no exclusion criteria were applied). Once full enrollment was reached, additional families turned away from the study were informed of opportunities for participating in other community-based family programs.

\section{Participants}

Four families were dual-parent and one was a single mother, thus $N=9$ parents (4 male and 5 female) participated. All of the participating youth were girls. The families appeared to be representative of the average resident in the target school district (93\% Caucasian; median household income $=\$ 39,000 ;$ U.S. Census, 2000).

\section{Procedures}

Sessions were held at the middle school building from 6:30 p.m. to 8:30 p.m. one night per week for seven consecutive weeks. The first hour of the session was spent with parents in one room with two group facilitators and youth in a separate room with two other group facilitators. The second hour of the program was spent with all participating family members together engaged in interactive activities. The SFP program is typically delivered by one parent facilitator and two youth facilitators. For this pilot, two parent facilitators were present, one male and one female, both of whom were themselves parents, a recommendation of the developers of SFP. The female facilitator was a Master's level prevention coordinator who was certified to teach SFP and received training in mindfulness from the first author. The male facilitator (the second author) has Ph.D. level training in clinical psychology and the expertise to deliver the mindfulness components. The youth facilitators were female graduate students who had been trained in the SFP curriculum and had experience with classroom teaching and the delivery of positive youth development programs.

All parent sessions were videotaped in order to address the first research aim regarding curriculum revisions. Each parent was asked to complete a brief, one-page process survey at the end of each weekly parent session that was designed to gauge their receptivity to the activities of the program (both new and existing), thus addressing the second aim. This survey instrument contained a list of all of the parent session activities of the session, with a 5-point Likert type response scale for parents to indicate how much time they felt should be spent on the activity, from "A lot less time" to "A lot more time." This response option format was selected because it might be possible for a parent to greatly enjoy an activity, but still feel that too much time was spent covering that topic. The third research question was explored during a focus group that was held for the parents one week after the final group session. Participants were given a $\$ 10$ gift card incentive for attending the focus group. At least one parent member of four of the five families attended the focus group ( $n=5$ parents). 


\section{Results}

\section{Integrating New Mindfulness Activities}

Review of the session videotapes revealed that several of the new mindfulness activities took longer to deliver than planned and needed to be reduced in length in order to stay within the one hour limit. Parents seemed to be very engaged with the new material, both from facilitator reports during debriefing with the first author, through direct observation, and through observation of the videotapes. A workgroup comprised of the authors of this report, the female parent facilitator, as well as two other individuals with expertise and training in parenting intervention and/or mindfulness, was convened to review the curriculum and the videotapes with the purpose of making further revisions. This work included consultation with the developer of the original SFP curriculum, Virginia Molgaard, Ph.D., to seek advice for retaining the integrity of the original program content while further integrating the concepts and practices of mindfulness and mindful parenting into the deep structure of the curriculum.

\section{Parent Receptivity}

The results from the post-session evaluations of each activity indicated that parents generally liked the new activities. On average, participants thought that the same or more time should be spent on the new mindfulness activities. The new activities that had the highest average rating were those that focused on mindful communication, noticing the emotions of parenting, and non-reactivity. See Table 1 for mean levels of parent activity ratings. In addition to the main mindfulness-based activities in each session, the fourth through the seventh group sessions had periods of guided compassion practice at the beginning and ending of the parent session. These brief periods of practice were each designed to focus on a particular aspect of compassion (e.g., compassion for oneself as a parent, compassion for one's child, compassion for one's own parents). Parents reported that less time should be spent on these activities as compared to the other new activities, as indicated by lower ratings (range: 2.5-2.87), although qualitative results suggest that participants thought the compassion practice was important and should not be eliminated.

\section{Perceived Changes in Parenting Behaviors}

Five parents participated in a post-intervention focus group in which they were allowed first to freely comment on what they liked and disliked about the program and its influence on their parenting. They then responded to specific questions about the intervention activities. Several themes were identified in the results from the focus group discussion. Most parents commented on their enhanced (or newfound) ability to avoid being reactive in interactions with their children. They reported (a) greater awareness of how their moods affect how they react, and (b) an increased rate of stopping and thinking before reacting in family situations. When asked about how 
Table 1 Mindfulness activity topics, session goals, and participant ratings of time to be spent on activities

\begin{tabular}{llll}
\hline Session & Topic & Goal & Rating \\
mean (SD)
\end{tabular}

Note: Rating response range: $1=$ "A lot less time" to $5=$ "A lot more time"

group participation had influenced their parenting interactions, one mother, "JB", said:

...I really find myself stopping and thinking about situations all the time, especially when they might be difficult...or an argument might be about to start.

Another mother, "KC", said:

...it really made me take a look at myself and how my moods affect to [sic] how I react and what's going on...or what's going on with the smaller ones makes you kinda [sic] react to what's going on with the older one...it has really helped to just almost calm myself when I see myself start to react a certain way...

One father, "DT", said:

[since participating] I find that the more I can remove the anger that I'm feeling from the situation, the more productive the solution becomes, and I can stop and think and feel and express not only how I am feeling, but it gives her [my daughter] a chance to express how she's feeling and gives me time, that's the important thing, gives me some time to understand how she's feeling and remember how old she is and that no matter what it is, it's not the end of the world. Usually it's a pretty minor thing, in the big scheme of things. 
Results of the focus group provided further insight into the findings from the weekly process surveys in that parent participants said that they did not enjoy the guided practice activities that were held at the beginning and ending of the sessions as much as they liked the other mindfulness activities. Parents reported difficulty concentrating and they expressed a desire to practice in silence on their own without as much verbal guidance from the facilitator. The participants also pointed out that taking a few moments to stop and be present at the beginning of the session was useful for quieting their minds after a busy or stressful day. The overarching response to the guided periods of practice was that shorter periods of practicing mindful awareness or compassion would be acceptable but that the setting was uncomfortable (e.g., hard, small chairs designed for children) and noisy (e.g., from youth activities being held in other rooms of the school) and they would prefer more periods of silence in lieu of frequent verbal instruction.

\section{Discussion}

Our view of mindful parenting involves parents intentionally paying attention to their child and to their own internal cognitive and affective reactions to things their child says and does, while doing their best to convey a nonjudgmental and caring attitude and regulate their behavioral reactions. If parents are able to bring these qualities to their parenting, it may enhance their ability to employ other new parenting skills that they learn through participation in family-focused intervention programs. Results of this small, uncontrolled pilot study suggest that parents found the additional mindfulness components to be both acceptable and useful. Parents' report of benefits from group participation included greater emotion regulation and an ability to cope better with stress in the family context. Areas that we identified for improvement of the curriculum in terms of feasibility and acceptability are: (a) condensing activities that took too long to deliver during this pilot (as revealed by results of the videotape review); and (b) refining the mindfulness practice instructions to include more periods of silence (versus verbal guidance) and by infusing more frequent, but shorter, periods of practice.

\section{Limitations and Future Directions}

As is the case for any small pilot study, limitations are clearly evident. This study was conducted solely to gauge feasibility of conducting further tests of a mindfulness-based model of family skills training and was geared toward answering specific research questions regarding participant receptivity to and acceptance of the curriculum adaptations. This study did not include a comparison group and the findings are to be interpreted with caution with regard to the potential for selection effects. Nonetheless, most of the results were positive and suggest the need for a broader scientific study of the effects of mindfulness-enhanced SFP. The next phase of this research will involve refining the curriculum based upon the feedback received from the parents in this pilot, the experience of the facilitators, the input of the expert workgroup, and consultation from the developer of the SFP curriculum. 


\section{Conclusion}

When parents are facing the burden of perceived stress from sources both inside the home (e.g., parenting demands, marital conflict) and outside the home (e.g., work overload), parents may be less able to parent the way they intend. Parents whose parenting goals have undergone a positive shift from participation in family-focused interventions (i.e., they ideologically embrace the new parenting skills being taught) sometimes report frustration at not being able to consistently utilize the new skills that they have gained through intervention participation. Mindfulness and mindful parenting practices may provide parents with the ability to parent more consistently and to parent more in accordance with their goals for effective parenting, even when they are experiencing stressful events. If parents are able to cultivate mindfulness in parenting, they may be more likely to implement new parenting practices on a daily basis and avoid overreacting to normative levels of conflict in the parent-adolescent relationship. Thus parents may be better equiped to achieve the SFP intervention goals of maintaining consistency in their discipline practices, adequately monitoring their teen, improving the quality of time spent with their child, and maintaining a warm and affectionate relationship. What is more, parents may themselves attain greater psychological and physical health through an enhanced ability to cope with stress stemming from the dual-developmental transition of entering midlife as their children are entering adolescence.

Acknowledgments This work was supported by the National Institute on Drug Abuse (T32 DA 017629) and the National Center for Complementary and Alternative Medicine (T32 AT 003997) through fellowships to the first author. Funding for the pilot study was provided by the Penn State Children, Youth, and Families Consortium. We thank the central Pennsylvania families who participated in this study for their helpful feedback. Special thanks to Virginia Molgaard and Richard Spoth for their support of this adaptation of SFP, Elaine Berrena for her role as co-facilitator of the mindfulness-enhanced parenting sessions, and Kimberly Cassidy for her work as CTC prevention coordinator. Portions of this paper were presented at the Society for Prevention Research annual meeting held in May 2007 in Washington, D.C.

Open Access This article is distributed under the terms of the Creative Commons Attribution Noncommercial License which permits any noncommercial use, distribution, and reproduction in any medium, provided the original author(s) and source are credited.

\section{References}

Abidin, R. R. (1992). The determinants of parenting behavior. Journal of Clinical Child Psychology, 21, 407-412.

Baer, R. A. (2003). Mindfulness training as a clinical intervention: A conceptual and empirical review. Clinical Psychology: Science and Practice, 10, 125-143.

Belsky, J. (1984). The determinants of parenting: A process model. Child Development, 55, 83-96.

Bishop, S. R. (2002). What do we really know about mindfulness-based stress reduction? Psychosomatic Medicine, 64, 71-84.

Carson, J. W., Carson, K. M., Gil, K. M., \& Baucom, D. H. (2004). Mindfulness-based relationship enhancement. Behavior Therapy, 35, 471-494.

Carson, J. W., Carson, K. M., Gil, K. M., \& Baucom, D. H. (2006). Mindfulness-based relationship enhancement in couples. In R. A. Baer (Ed.), Mindfulness-based treatment approaches: Clinician's guide to evidence base and applications (pp. 309-331). Amsterdam: Elsevier. 
Collins, W. A. (1990). Parent-child relationships in the transition to adolescence: Continuity and change in interaction, affect, and cognition. In R. Montemayor, G. R. Adams, \& T. P. Gullotta (Eds.), From childhood to adolescence: A transitional period (pp. 85-106). London: Sage.

Conger, R. D., Ge, X., Elder, G., Lorenz, F., \& Simons, R. (1994). Economic stress, coercive family process, and developmental problems of adolescents. Child Development, 65, 541-561.

Dix, T. (1991). The affective organization of parenting: Adaptive and maladaptive processes. Psychological Bulletin, 110, 3-25.

Dix, T., Ruble, D. N., Grusec, J. E., \& Nixon, S. (1986). Social cognition in parents: Inferential and affective reactions to children at three age levels. Child Development, 57, 879-894.

Dumas, J. (2005). Mindfulness-based parent training: Strategies to lessen the grip of automaticity in families with disruptive children. Journal of Clinical Child and Adolescent Psychology, 34, 779-791.

Duncan, L. G., Coatsworth, J. D., \& Greenberg, M. T. (2009). A model of mindful parenting: Implications for parent-child relationships and prevention research. Clinical Child and Family Psychology Review (in press).

Folkman, S. (1997). Positive psychological states and coping with severe stress. Social Science and Medicine, 45, 1207-1221.

Germer, C. K. (2005). Mindfulness: What is it? What does it matter? In C. K. Germer, R. D. Siegel, \& P. R. Fulton (Eds.), Mindfulness and psychotherapy (pp. 3-27). New York: Guilford Press.

Gottman, J. M., Katz, L. F., \& Hooven, C. (1996). Parental meta-emotion philosophy and the emotional life of families: Theoretical models and preliminary data. Journal of Family Psychology, 10, 243-268.

Hawkins, J. D., Catalano, R. F., \& Miller, J. Y. (1992). Risk and protective factors for alcohol and other drug problems in adolescence and early adulthood: Implications for substance abuse prevention. Psychological Bulletin, 112, 64-105.

Kabat-Zinn, J. (1990). Full catastrophe living: Using the wisdom of your body and mind to face stress, pain and illness. New York: Dell Publishing.

Kabat-Zinn, J. (2003). Mindfulness-based interventions in context: Past, present, and future. Clinical Psychology: Science and Practice, 10, 144-156.

Kabat-Zinn, M., \& Kabat-Zinn, J. (1997). Everyday blessings: The inner work of mindful parenting. New York: Hyperion.

Kumpfer, K. L., \& Alvarado, R. (2003). Family-strengthening approaches for the prevention of youth problem behaviors. American Psychologist, 58, 457-465.

Kumpfer, K. L., Olds, D. L., Alexander, J. F., Zucker, R. A., \& Gary, L. E. (1998). Family etiology of youth problems. In R. S. Ashery, E. B. Robertson, \& K. L. Kumpfer (Eds.), Drug abuse prevention through family interventions (pp. 42-77). Rockville, MD: National Institute on Drug Abuse.

Larson, R. W., \& Richards, M. H. (1994). Family emotions: Do young adolescents and their parents experience the same states? Journal of Research on Adolescence, 4(4), 567-583.

Lazarus, R. S., \& Folkman, S. (1984). Stress, appraisal, and coping. New York: Springer.

Molgaard, V., \& Spoth, R. (2001). The strengthening families program for young adolescents: Overview and outcomes. In S. Pfeiffer \& L. Reddy (Eds.), Innovative mental health interventions for children: Programs that work (pp. 15-29). Binghamton, NY: Haworth Press.

Mroczek, D. K. (2004). Positive and negative affect at midlife. In O. G. Brim, C. D. Ryff, \& R. C. Kessler (Eds.), How healthy are we? A national study of well-being at midlife (pp. 205-226). Chicago: University of Chicago Press.

Silverberg, S. B. (1996). Parents' well-being at their children's transition to adolescence. In C. D. Ryff \& M. M. Seltzer (Eds.), The parental experience in midlife (pp. 215-254). Chicago: The University of Chicago Press.

Spoth, R. L., Clair, S., Greenberg, M. T., Redmond, C., \& Shin, C. (2007). Toward dissemination of evidence-based family interventions: Maintenance of community-based partnership recruitment results and associated factors. Journal of Family Psychology, 21, 137-146.

Spoth, R., \& Redmond, C. (2002). Project Family prevention trials based in community-university partnerships: Toward scaled-up preventive interventions. Prevention Science, 3(3), 203-221.

Spoth, R., Redmond, C., Shin, C., \& Azevedo, K. (2004). Brief family intervention effects on adolescent substance initiation: School-level growth curve analyses 6 years following baseline. Journal of Consulting and Clinical Psychology, 72, 535-542.

Spoth, R., Redmond, C., Trudeau, L., \& Shin, C. (2002). Longitudinal substance initiation outcomes for a universal preventive intervention combining family and school programs. Psychology of Addictive Behaviors, 16(2), 129-134. 
Steinberg, L. (2001). We know some things: Parent-adolescent relationships in retrospect and prospect. Journal of Research on Adolescence, 11, 1-19.

Steinberg, L., \& Silk, J. S. (2002). Parenting adolescents. In M. H. Bornstein (Ed.), Handbook of parenting: Children and parenting (2nd ed., Vol. 1, pp. 103-133). Mahwah, NJ: Lawrence Erlbaum Associates.

Taylor, T. K., \& Biglan, A. (1998). Behavioral family interventions for improving child-rearing: A review of the literature for clinicians and policy makers. Clinical Child and Family Psychology Review, 1, 41-60. 